\title{
Parenting style and conduct problems in children: A report of deliberate self- poisoning in a Nigerian child
}

\author{
M F Tunde-Ayinmode, MB BS, FMCPsych \\ O A Adegunloye, BM BCh, FWACP \\ Department of Behavioural Sciences, University of Ilorin \\ Teaching Hospital, llorin, Nigeria
}

A correlation between unhealthy parenting styles and child psychopathology has been established. This case report describes how chronic harsh paternal parenting caused a young boy to deliberately poison himself with organophosphate chemicals (rat poison). This report is intended to stimulate the interest of physicians and psychiatrists in parenting style research and in how parenting style modification can be a therapeutic and preventive tool.

Parenting style can be described as all strategies (behaviours, attitudes and values) parents use to interact with their children and influence their physical, emotional, social and intellectual development.' Theories concerning parenting style are not simply about the individual behaviour of parents but refer to a pattern of bi-directional relationships between parents and child.

The driving force behind parenting style research has been the physical and psychosocial well-being of children and families. There has been a drive towards identifying negative and positive parenting attitudes and practices or behaviours and manipulating these appropriately towards a better physical and psychosocial outcome, hence preventing ill health and promoting well-being. Parenting style is important, because several reports indicate that it predicts how children perform in the domains of social competence, psychosocial development, academic performance and problem behaviour. ${ }^{24}$

An outstanding analysis of this issue is that of Diana Baumrind, ${ }^{5}$ who conceptualised four dimensions of parent-child interaction, namely disciplinary strategies; warmth and nurturance; communication styles; and expectation of maturity and ability to self-control. ${ }^{5}$ On the basis of these dimensions, she identified three parenting styles: authoritative, authoritarian, and indulgent or permissive. Maccoby and Martin re-conceptualised the parent-child relationship to two dimensions, consisting of degrees of parental responsiveness to psychosocial needs, which include warmth and support, and parental demands from their children (parental 'demandingness', i.e. how parents control their children's behaviour to achieve psychosocial objectives). Parental responsiveness is reported to predict social competence and psychosocial functioning, while parental 'demandingness' is associated with instrumental competence (academic performance and problem behaviour). This approach led to the identification of a fourth parenting style, i.e. uninvolved or neglectful styles of parenting.

This integrated typology of four parenting styles still forms the theoretical underpinning of much research on parenting styles, and its correlates and outcome. ${ }^{2}$ These four styles may be described as follows: authoritative parents are high on both demanding and responsiveness measures; authoritarian parents are high on demanding but low on responsiveness measures; indulgent parents are high on responsiveness and low on demanding measures; and uninvolved parents are low on both demanding and responsiveness measures.

Research into child behaviour outcomes associated with each parenting style has traditionally suggested that authoritative parenting has benefits over the others. Generally, children of such parents perform well in all domains (social competence, psychosocial development and instrumental competence), "'having more friends, better school performance, more self-discipline and emotional self-control. Children from uninvolved families are poorer in all the domains, ${ }^{3,4,7}$ while those with authoritarian parents may do well academically and behaviourally but are poor in social skills, have low self-esteem and an increased level of depression and risk of suicide. ${ }^{3,7}$ Indulgent parenting produces children more likely to be involved in problem behaviours (substance abuse, deviant behaviour and school misconduct); they have a lower level of academic performance but better social skills and lower levels of depression. ${ }^{3}$

It is important to note that parenting styles vary not only with geography, religious belief, culture and specific families, but also between and within individual parents. 8,9 Factors that determine parenting styles have been studied extensively, 8,9 they include family and personal values, parental culture, religion and personality, temperament of parents and of the child, socio-economic status and ethnicity. ${ }^{8}$ Human behaviour genetic research suggests that parenting style may be heritable;, 9.10 e.g. genetic factors may play substantial roles in eliciting warmth from parents and influence parental protectiveness and authoritarianism. ${ }^{10}$

There is acknowledgment of the potential for dissimilar maternal and paternal parenting styles and of its influence on the childparent interaction and the eventual psychosocial outcome for the child." Use of different styles by parents becomes important 
when they are conflicting;" this potentially creates confusion and inconsistencies in the overall reaction of a child to parenting. Parental conflicts and marital problems may undermine parental competence or competent parental functioning and involvement. For example, the use of authoritarian and neglectful styles concurrently by parents may lead to marital and parenting distress and psychopathology in the children. ${ }^{12}$

One of the major instruments of the parenting task is the control strategy used. 5.6 This often involves some form of disciplinary action. Corporal punishment is still a widely practiced disciplinary method for children. ${ }^{13,14}$ In many parts of Africa it is still the rule rather than the exception; it is a practice supported by tradition, religion and the extended family. ${ }^{13}$ It has been defined as use of physical force with the intention of causing pain but not injury for the purpose of correction or control of a child's behaviour. ${ }^{14}$

Corporal punishment may be 'normative' (appropriate) or 'abusive' (inappropriate), depending on the method, its severity and frequency, the age of the child being punished and the context. ${ }^{14}$ Because of its potential to escalate, the dividing line between appropriate and abusive punishment can be very thin; crossing the boundary can be quite easy. ${ }^{1315}$ Parents who use corporal punishment often graduate to harmful forms such as using belts, electrical cords or other objects, or kicking and punching. ${ }^{14}$ The African Network for Prevention and Protection against Child Abuse and Neglect (ANPPCAN) defines child abuse as acts that intentionally or unintentionally endanger the physical health, and emotional, moral and educational welfare of children. ${ }^{13}$

Child abuse is a global problem, and in Nigeria it is not only prevalent but still largely neglected despite evidence that it is a risk factor for psychiatric disorder. ${ }^{1517}$ For example, one study found physical abuse to be a risk factor for child and adolescent suicidal behaviour in Nigeria. ${ }^{18}$

Closely related to and interdependent with child abuse is spousal abuse, another form of family violence also common globally. ${ }^{16,18}$ In Nigeria, the patriarchal tradition, in which control of family and society rests with males, allocates a subordinate position to women and children and predisposes them to abuse or family violence. ${ }^{16}$ This apparent gender inequality is also embedded in the cultural, socio-political and economic systems and gives impetus to family violence, which is a known psychopathological risk factor for mothers and their children. ${ }^{10,18}$

The theoretical classification of parenting styles may not be easily applied in the clinical setting, where it is often adverse outcomes that point to potentially problematic styles; very seldom is the reverse the case. In clinical settings, identifying problematic parenting styles before they result in psychiatric and social disabilities in children, and being able to modify them, are major challenges for child and adolescent psychiatry.

\section{Case report}

A 12-year-old boy in his second year at junior secondary school, weighing $31 \mathrm{~kg}$ and $1.4 \mathrm{~m}$ tall, was referred to the child and adolescent psychiatry clinic from the paediatrics department of University of Ilorin Teaching Hospital. He was accompanied by his parents and paternal grandmother.

He had spent 3 days in the emergency paediatric unit after deliberate ingestion of an organophosphate (rat poison), for which he had received gastric lavage, intravenous fluids and close monitoring, among other treatments. Once considered medically stable, he was referred for psychiatric evaluation and management. This revealed that the boy had deliberately tried to harm himself without fatal intentions. The day before the incident, he had had a frightening encounter with his teacher, who beat him severely and threatened to report him to his father because he frequently did not complete his assignments. The main focus of the boy's anxiety was the threat to report his behaviour to his father, whom he feared greatly. He confessed disliking his teacher because of excessive use of corporal punishment, which appeared to have been tacitly approved by his father.

The boy's mother and paternal grandmother were of the opinion that his father was overbearing and threatening towards the family. It was the norm in the family to use corporal punishment, which often entailed flogging. Episodes of 'discipline' were often intolerable for the patient's mother, who believed that the punishment was too harsh, as physical injuries sometimes occurred. Attempts by her to intervene were often met with verbal abuse and threats of physical violence.

These episodes of 'discipline' were triggered by the boy's conduct problems, which had gradually affected his school work. The main complaints were too much playing, lying, and physical aggression towards his siblings.

In the index 'discipline' episode, our patient had thought he could evade his father's punishment by being 'taken ill' as a result of self-poisoning. His parents were informed of the poisoning immediately by his grandmother, who had been informed by his younger brother. He was brought to hospital within 20 minutes of the ingestion.

Assessment of family structure and functioning revealed a monogamous structure consisting of 2 married parents living together with 5 children, all boys. The patient was the eldest, and the youngest was 6 years old. Information from the parents, the patient and his paternal grandmother suggested that interactions within the family were essentially cordial and moderately harmonious, except for the intermittent episodes of conflict arising from disciplinary issues. The father explained that corporal punishment was part of his cultural and traditional methods of child rearing, and he was not of the opinion that he had exceeded the norm. He explained that his son's continuing 
decline in academic performance was due to his excessive playing, and that this conduct fuelled the episodes of 'discipline'. The patient's mother and paternal grandmother were worried because the boy beat his younger siblings severely. There was no family history of mental illness, epilepsy or substance abuse.

Exploration of personal history revealed that the mother's pregnancy with our patient had been normal, as had his delivery and developmental milestones. He related well to relatives and friends. At school he had done well initially and was in the top 5 of his class, but had deteriorated into the 20s in the year preceding the presenting crisis. His parents blamed his conduct on excessive involvement in football. There was no suspicion that he abused drugs or any other psychoactive substances.

Mental state assessment revealed a boy who was alert, well informed, tidy, calm and co-operative. He had no abnormal movements, and his speech was spontaneous, coherent and rational. His mood was considered 'happy' and his affect appropriately reactive; no perceptual disturbances or thought abnormalities were detected. He was well orientated to time, place and person; attention and concentration were good, as were immediate recall and short- and long-term memory. Intellectual assessment showed average results, except for some difficulties with arithmetic. His judgement and insight were good. Physical examination, including neurological examination, revealed no abnormalities.

An assessment of deliberate self harm (International Statistical Classification of Diseases, 10th revision (ICD-10) X68 intentional poisoning by exposure to pesticide) in a mentally stable child was made. Management was initiated along the following lines: (i) psycho-education of the parents with the intention of informing and changing parenting skills and style; (ii) psycho-education of the patient to resolve conduct concerns; (iii) education of parents and child on effective study skills and coping skills; (iv) monitoring the child and his family for compliance with the treatment plan and maintenance of improvement in mental health; and (v) advising the child's parents to pay attention to his life issues, including his relationship with his teacher.

Follow-up revealed that after 4 subsequent visits, in which the counselling themes and goals were restated and reinforced, the family was stable and the patient was doing well at home and at school, returning to the top 5 in his class at the end of the following academic session.

\section{Discussion}

Many cultural practices in Nigeria invest parents, particularly fathers, with enormous powers to discipline their children. ${ }^{16}$ Except for the conflicts highlighted, this family would therefore probably be assessed without hesitation as stable, supportive and nurturing as far as physical and social development of the child was concerned. In addition, the dynamics reflected a typical Nigerian family with a mixture of a dominant and forceful paternal presence and a 'behind the scenes but potent' maternal role. Male authority and unquestioning child compliance are considered very important in many Nigerian families and are backed by culture, religion and sometimes even the judicial system. ${ }^{13}$ Acted out in marriage and family life, this dominance by the male gender subjects mothers and their children to the risk of abuse. ${ }^{15}$

In the context of deliberate self-harm, it was important to determine whether the child was vulnerable to psychiatric problems before the crisis. Firstly, we needed to analyse the social and psychological pathway to this dysfunctional state and use the information obtained to manage the case, and secondly we needed to identify pre-existing risk factors, particularly the quality of parenting skills and competencies, to assist in preventive care.

Frequent parental conflicts, especially if associated with abuse (child and/or mother) as in this case, are a risk factor for child psychiatric disorders. ${ }^{17.19}$ Studies confirm that school achievement and success are affected by parental involvement and parenting style. ${ }^{20}$ Conflicting or contradictory parenting styles can negatively affect parental involvement, and may create confusion and inconsistency in child-parent interaction. Eventually the child's academic performance may be affected..$^{20}$

In this case, there was apparent dissonance between the maternal and paternal parenting styles, and the boy's mother was frustrated by what she perceived as her husband's high-handedness. The father appeared to be authoritarian in style, while the mother might have been more authoritative or perhaps indulgent. It is highly probable that these dissimilar parenting styles influenced the child's conduct problem and decline in academic performance.

Conflict between father and mother is not abnormal in family dynamics, but gender inequality may tilt the balance, creating additional difficulties. A closer analysis of this family reveals the pervasive role of gender inequality; it diminished the moderating role that the mother and even the paternal grandmother could have had on the entire process of family interaction. Gender inequality, while a gradually declining global phenomenon, is still a serious problem in Nigeria, ${ }^{16,18}$ where girls suffer educational discrimination, with consequential economic disadvantage, and women enter marriage with a subordinate role in decision making, even about decisions that directly affect their children, and are also at risk of partner abuse. ${ }^{16,18}$

Brought up in an environment where discipline had been similar, the boy's father did not feel that his parenting style was abnormal; it conformed to his family tradition, particularly concerning his eldest child. It is recognised that patterns of parenting behaviour may be trans-generational; although this is not inevitable, both harsh and supporting styles may be transmitted intergenerationally. ${ }^{9.10}$ This fact should not in any way diminish the scrutiny directed at the 
impact of parental practice and style on psychosocial outcomes for children.

With his controlling behaviour escalating to involving his wife in the form of verbal and emotional abuse, there were risks for psychopathology in the family, especially for our patient and his mother. The fact that the boy was already bullying his younger siblings may well be an example of this negative effect. Children growing up in violent environments are more likely to be violent towards others, especially their spouses in adult life. . $^{14,16}$ Breaking the cycle of abuse and violence is a major challenge for families and mental health workers.

Although child abuse is prevalent in Nigeria, it remains a neglected problem. Resources allocated to detection and prevention are inadequate, and the protection offered by the extended family is waning, especially in urban centres. ${ }^{13,15,16}$

There was enough evidence in this case to suggest some degree of family violence; mother and child were being abused by the father, yet it was not reported to any child protection agency or to the police. Child abuse in Nigeria, like other forms of family violence, is under-reported even by the medical community, despite its potential adverse psychosocial effects and laws to protect the rights of children. ${ }^{13,15,16}$ The medical community is often reluctant to get involved beyond education and counselling. Apart from time constraints, the process of getting protection agencies or the police to intervene is complex and frustrating, and outcomes are still predictably poor ${ }^{16}$ because of socio-cultural encumbrances. Firstly, family violence is often considered strictly a private affair; and secondly, culture and religion, which should be primary interventional points, both seriously discourage and constrain movement to other levels of intervention. ${ }^{13,16}$

In our case, it was also important to determine whether or not the family could provide a stable enough environment for its problems to be addressed. The patient's nuclear and extended families were essentially intact and functioning. The paternal grandmother played a significant role in protecting and caring for him when his safety was endangered. She was called first after his self-poisoning, and she took immediate action. She had also on occasion cautioned her son (the boy's father) to moderate his disciplinary style. The child's mother had also protested to her husband despite his often belligerent attitude concerning the matter. Additional family counselling succeeded in making the environment more conducive to the child's psychosocial development and subsequent improvement in his conduct and academic problems.

\section{Conclusion}

Since parenting styles have both medical and psychiatric implications, they should be of more concern to doctors. It would be useful for clinicians to focus on parenting characteristics and styles as they affect children and adolescents with psychiatric illness, particularly those with conduct disorder. Because of the factors that influence parenting styles, and the fact that such behaviours are not necessarily deliberately taught or learnt, they may be difficult to change. This should not discourage attempts to modify parental behaviour if it is abusive or causing distress.

In the case reported here, efforts were made to modify the styles used by the parents through counselling sessions and family meetings involving the parents, the child, some siblings and one grandparent.

\section{References}

Darling N Steinberg L. Parenting as context: An integrated model. Psychol Bull 1993; 1 13(3):487-496.

2. Cripps K, Zyromski B. Adolescent psychological wellbeing and perceived parental involvement: implication of parental involvement in middle school. Research in Middle Level Education Online 2009:33:1-13

3. Weiss $L H$ and Schwarz JC. The relationship between parenting types and older adolescents' personality, academic achievement, adjustment, and substance use. Child Development 1996;67(5):2101-2114

4. Baumrind D. Pattern of parental authority and adolescent autonomy. New Directions for Child and Adolescent Development. 2005;108(Summer):61-69.

5. Baumrind D. Child care practices anteceding three patterns of preschool behaviour Genetic Psychology Monograph 1967:75(1):43-88.

6. Maccoby EE, Martin JA. Socialization in the context of the family: Parent-child interaction. In: Mussen PH, Hetherington EM, eds. Handbook of Child Psychology. Vol. 4. Socialization, personality, and social development. 4th ed. New York: Wiley, 1983:1-101

7. Steinberg L, Lamborn SD, Darling N, Mounts NS, Dornbusch SM. Over-time changes in adjustment and competence among adolescent from authoritative, authoritarian, indulgent and neglectful families. Child Development 1994; 63(3):754-777.

8. Bornstein $M H$, Zlotnik D. Parenting style and their effects. Encyclopaedia of Infant and Early Childhood Development. Elsevier, 2008:496-509

9. Belsky J. Social-contextual determinants of parenting. In: Tremblay RJ, Barr RE, Peters R, eds. Encyclopaedia of Early Childhood Development [online]. Montreal: Centre of Excellence for Early Childhood Development, 2005: 1-6. http://www. childencyclopedia.com/documents/BelskyANGxp-Parenting. pdf laccessed 15 December 2010).

10. Kendler KS. Parenting: a genetic epidemiological perspective. Am J Psychiatry 1996; 153:1 1-20

11. Gamble WC, Ramakumar S, Diaz A. Maternal and paternal similarities and differences in parenting: An examination of Mexican-American parents of young children. Early Child Res Q 2007;22111:72-88.

12. Nanthamongkelcahai $S$, Ngaosusit $C$, Munsawengsub $C$. Influence of parenting styles on development of children aged three to six years old. I Med Assoc Thai 2007;90(5):971-976

13. Umobong ME. Child abuse and its implication for the educational sector in Nigeria OGIRISI: A New Journal of African Studies 2010:7:106-1 18.

14. Gershoff RT. Parental corporal punishment associated child behaviour and experience: a meta-analysis and theoretical review. Psychol Bull 2002; 1 28:539-579.

15. Ebigbo PO. Child abuse and neglect in Nigeria - a situational analysis. Niger Pop 1993;Oct-Dec: 10-14.

16. Egbue NG. Socio-cultural factors in Nigeria male youth violence: Relationship with education and employment. J Soc Sci 2006; 12(1):1-10.

17. Seng AC, Prinz RJ. Parents who abuse: what are they thinking? Clin Child Fam Psychol Rev 2008; 11 (4): 163-175.

18. Kawewe S, Dibie R. United Nations and the practice of women and children abuse in Third World nations. Social Justice 1999;26(1):78-98.

19. Omigbodun OO, Dogra N, Esan O, Adedokun B. Prevalence and correlates of suicidal behaviour among adolescent in South-West, Nigeria. Int I Soc Psychiatry 2008; 54:34-46

20. Jeynes $W H$. A meta-analysis of the relationship of parental involvement to urban elementary school academic achievement. Urban Education 2005;40(3):237-269. 